\title{
Factor V Leiden G1691A and prothrombin G20210A mutations among Palestinian patients with sickle cell disease
}

\author{
Fekri Samarah ${ }^{1 *}$ (D) and Mahmoud A. Srour ${ }^{2,3}$
}

\begin{abstract}
Background: Vascular thrombosis is an important pathophysiological aspect of sickle cell disease (SCD). This study aimed to investigate the prevalence and clinical impact of factor V Leiden G1691A (FVL) and prothrombin G20210A mutations among Palestinian sickle cell disease (SCD) patients.

Methods: A total of 117 SCD patients, including 59 patients with sickle cell anemia (SS), 33 patients with sickle $\beta$-thalassemia and 25 individuals with sickle cell trait (AS) were studied. The control group consisted of 118 healthy individuals. FVL and prothrombin G20210A mutations were determined by RFLP PCR.

Results: Analysis of the clinical history of SCD patients revealed that seven patients have had vascular complications such as ischemic stroke or deep vein thrombosis. In SCD patients, the inheritance of the FVL mutation showed a significantly higher incidence of pain in joints, chest and abdomen as well as regular dependence on blood transfusion compared to SCD with the wild type. Age- and sex-adjusted logistic regression analysis revealed a significant association between FVL and sickle cell anemia with an odds ratio (OR) of 5.6 (95\% confidence intervals [Cl] of 1.91-39.4, $P=0.039$ ) in SS patients. However, increased prevalence of the FVL in AS subjects and sickle $\beta$-thalassemia patients was not statistically significant compared to controls (OR 3.97, 95\% Cl 0.51-28.6, $P=0.17$ and OR 3.59, 95\% Cl 0.35-41.6, $P=0.26$, respectively). The distribution of prothrombin G20210A mutation among SCD patients compared to controls was not significantly different, thus our findings do not support an association of this mutation with SCD.
\end{abstract}

Conclusions: FVL was more prevalent among SS patients compared to controls and it was associated with higher incidence of disease complications among SCD patients.

Keywords: Factor V Leiden, Prothrombin G20210A, Sickle cell disease, Palestine

\section{Background}

Sickle cell disease (SCD) is an inherited disorder of $\beta$-globin gene and $\mathrm{HbS}$ was one of the first structural variants of hemoglobin to be discovered. HbS results from the substitution of valine for glutamic acid at the sixth codon of $\beta$-globin gene. SCD is a term used to describe not only homozygous HbSS but also includes cases of compound heterozygotes with other $\beta$-globin gene disorders such as $\beta$-thalassemia $\left(\beta^{0}\right.$ or $\left.\beta^{+}\right)$[1]. Although sickle hemoglobin is the product of one mutated gene, the disease phenotype is multigenetic, and gene polymorphisms

\footnotetext{
* Correspondence: fekri.samarah@aauj.edu

${ }^{1}$ Department of Medical Technology, Faculty of Allied Health Sciences, Arab American University in Jenin, Jenin, Palestine

Full list of author information is available at the end of the article
}

dictate the different variations seen in SCD patients [2]. The contribution of inherited thrombophilia to the pathophysiology of SCD has been tackled by many reports. The mortality rate of SCD patients has been shown to increase with the presence of acute chest syndromes, as well as occlusive strokes [3]. In addition, a hypercoagulable state in SCD patients has been established that is attributed to several factors including the interaction of sickle cells with the endothelium. The adherence of sickle cells to endothelium is attributed to the increased levels of circulating interleukins as well as platelet and monocyte activation [4].

The coinheritance of genetic thrombophilia thus may exacerbate the hypercoagulable state in SCD patients. The identification of SCD patients with risk factors for developing thrombosis should be valuable in the 
management and prevention of vasoocclusive crisis through pharmacological intervention using antithrombotic medications [5].

A well-established genetic predisposition to venous thrombosis that occurs in approximately 5\% of Caucasian populations is a single-point mutation in the gene encoding coagulation factor V (G1691A) or Factor V Leiden (FVL). FVL is associated with a 7 -fold increased risk of venous thrombosis in heterozygote individuals and a 50 -fold to 100 -fold increased risk of venous thrombosis in homozygote individuals [6]. The second most common risk factor for venous thrombosis is the prothrombin G20210A mutation which is also specific for Caucasian populations (2\%) [7]. The prothrombin G20210A mutation is associated with a higher plasma prothrombin levels and a three-fold greater risk of venous thrombosis.

In this study, the prevalence of FVL G1691A and prothrombin G20210A mutation was assessed in 117 SCD individuals and 118 healthy controls from the West Bank of Palestine.

\section{Methods}

\section{Study design and subjects}

A cross-sectional study was conducted with the objective to investigate the prevalence and clinical impact of factor V Leiden G1691A (FVL) and prothrombin G20210A mutations among Palestinian (of Caucasian race) sickle cell disease (SCD) patients. Sickle cell and sickle $\beta$ thalassemia patients were all recruited from Al-Watani Hospital in Nablus. This Hospital is the referral center for these disorders in Northern Governorate of Palestine. And the majority of Sickle cell anemia cases in Palestine are registered in the Northern Governorates of Palestine. For selection of the patients, the medical files of patients registered as Sickle cell anemia or Sickle $\beta$-thalassemia $(\mathrm{S} / \beta$ thal) at Al-Watani Hospital were reviewed and patients that fulfilled the inclusion criteria were contacted and asked to participate. Information about the health status or clinical complications was collected from medical files. In addition, all patients who accepted to participate in the study were asked to to state their age, sex and confirm their diagnosis using an interview-based questionnaire. The inclusion criteria were: confirmed diagnosis of Sickle cell anemia, Sickle cell trait, or $\mathrm{S} / \beta$ thal, did not experience vascular crisis or chest syndrome at time of sampling, did not show thrombotic events or have family history of thrombosis, and were not transfused during the last 4 weeks prior to sample collection. Patients comprised 117 individuals with SCD, of whom 59 were SS (30 males and 29 females) aged $16 \pm 9.9$ years (mean \pm SD), 25 were AS (14 males and 11 females) aged $21.2 \pm 9.1$ years (mean $\pm \mathrm{SD}$ ), and 33 were $S / \beta$ thalassemia (18 males and 15 females) aged $15.1 \pm 5.1$ years (mean \pm SD). The control group included 118 apparently healthy individuals (77 males and 41 females) aged $20.6 \pm 5.5$ years (mean $\pm \mathrm{SD}$ ). The inclusion criteria for controls were: individuals did not experience any past or current thrombotic events or had a family history of venous or arterial thrombosis (including stroke, deep venous thrombosis or pulmonary embolism), and were recruited either from blood donors, or medical staff. Blood samples were collected after a written informed consent was obtained from each patient or their guardians/parents before entry to the study.

\section{Main outcome measures}

The primary outcome measure was the frequency of FVL and Prothrombin G20210A mutations among SCD compared to controls. Secondary outcomes included type and frequency of clinical complications among SCD positive for FVL or/and Prothrombin G20210A mutations compared to those with wild type genotype.

\section{Laboratory methods}

Hematological data including complete blood counts and red cell indices were measured using a cell counter Sysmex Kx21 (Kobe, Japan) for all study patients and controls.

The sickle cell phenotype was diagnosed by conventional electrophoresis methods (cellulose acetate at alkaline and acid $\mathrm{pH}$ ) [8]. In addition, hemoglobin electrophoresis was performed for controls to ascertain absence of $\beta$ thalassemia trait. DNA was isolated from peripheral blood leukocytes with the QIAamp Blood kit (QIAGEN, Heldin/ Germany) according to manufacturer's recommendations and kept at $-20{ }^{\circ} \mathrm{C}$ until analyzed. DNA analysis was used to confirm the diagnosis of sickle cell anemia, sickle cell trait and sickle $\beta$-Thalassemia. Homozygosity or heterozygosity for the $\beta^{S}$ mutation was ascertained by polymerase chain reaction (PCR) followed by digestion with the restriction enzyme DdeI [9]. The $\beta^{\mathrm{S}}$ haplotype was determined by RFLP PCR as described earlier [10]. The Benin $\beta^{S}$ haplotype was the most predominant haplotype among our patients corresponding to about $88 \%$ of all haplotypes. The $\beta$-thalassemia alleles in $S / \beta$ thal patients were screened by PCR reverse dot blot (PCR-RDB) technique [11].

\section{Detection of factor $\mathbf{V}$ Leiden mutation}

The FVL G1691A mutation was identified as described earlier [6]. Briefly, a 267-bp fragment of exon 10 of coagulation factor $\mathrm{V}$ gene was amplified using the following primer pair: forward primer 5'-TGC CCA GTG CTT AAC AAG ACC A-3'; reverse primer 5' -TGT TAT CAC ACT GGT GCT AA-3'. The PCR product was digested with MnlI restriction enzyme and analyzed on a $3 \%$ agarose gel. The normal $\mathrm{G}$ allele was confirmed by the presence of three fragments (163, 67, and $37 \mathrm{bp}$ ), while the mutant A allele was confirmed by the presence of two fragments (200 and $67 \mathrm{bp}$ ). 


\section{Detection of prothrombin G20210A mutation}

The prothrombin G20210A mutation was identified as described earlier [7]. Briefly, a 345-bp fragment spanning the 3 ' sequence of exon 14 and 5 ' sequence of 3 '-untranslated region of the prothrombin gene was amplified using the primer pair: forward 5'-TCT AGA AAC AGT TGC CTG GC-3' and reverse 5' -ATA GCA CTG GGA GCA TTG AAG C-3'. The PCR product was digested with HindIII restriction enzyme and analyzed on a 3\% agarose gel. The presence of intact $345 \mathrm{bp}$ fragment on the agarose gel indicates the presence of normal $\mathrm{G}$ allele, while the presence of two fragments (322 and $23 \mathrm{bp}$ ) indicates the presence of mutant A allele.

\section{Statistics}

Allele frequency was calculated using the gene counting method. The observed genotype frequencies for FVL and prothrombin G20210A mutations among patients and healthy individuals were compared and tested for Hardy-Weinberg equilibrium using the Chi-Square test. The significance of the difference of observed alleles and genotypes between the groups was tested using the ChiSquare analysis after grouping individuals as normal and heterozygous/homozygous carriers of the FVL and prothrombin G20210A mutations. Odds ratio (OR), both unadjusted and age- and sex-adjusted as well as their 95\% confidence intervals (CI) were calculated using SPSS logistic regression to estimate the relative risk for the disease. A $P$-value $<0.05$ was considered statistically significant. The SPSS software package version 15.0 was used for the statistical analysis.

\section{Results \\ Clinical characteristics}

The general and hematological characteristics of study patients are summarized in Table 1 . The type of $\beta$ thalassemia mutation was determined in 26 out of 33 sickle/ $\beta$-thalassemia patients. Seven different mutations were determined: IVS-I-1 $(\mathrm{G} \rightarrow \mathrm{A})$, IVS-II-1 $(\mathrm{G} \rightarrow \mathrm{A})$, Codon $39(\mathrm{C} \rightarrow \mathrm{T})$, Fs8 $(-\mathrm{AA})$, Codon 30 (AGG $\rightarrow$ ACG), IVS-I-110 $(\mathrm{G} \rightarrow \mathrm{A})$, and Codon $37(\mathrm{G} \rightarrow \mathrm{A})$. Around $80 \%$ of the later mutations were associated with $\beta^{0}$-thalassemia. Relevant clinical information was recorded in all SCD patients. Vascular occlusive cerebral disease (stroke) was diagnosed in four patients based on computerized tomography and focal neurologic defect. One patient out of four was with Sickle $/ \beta^{0}$-thalassemia with IVS-II-1 $(\mathrm{G} \rightarrow \mathrm{A})$ mutation, the remaining three patients were with sickle cell anemia (SS). In addition, three patients were diagnosed with venous thrombosis. The later three patients developed a thrombosis associated with central vein catheter; the diagnosis was based on clinical data. For chronic complications leg ulcers were present in nine patients ( 6 males, 3 females), all were with sickle cell anemia (SS). X-ray documented avascular bone necrosis (AVN) in seven patients ( 4 females, 3 males), two of them were with Sickle $/ \beta^{0}$-thalassemia with IVS-II- $1(\mathrm{G} \rightarrow \mathrm{A})$ and Codon 39 $(\mathrm{C} \rightarrow \mathrm{T})$ mutations. Priapism occurred at the post-pubertal

Table 1 Charecteristics of SS, AS, S/ $\beta^{\text {Thal }}$ patients and controls. Data are presented as mean \pm SD for the age and hematological data and frequency for sex and clinical complications

\begin{tabular}{|c|c|c|c|c|}
\hline & AS $(n=25)$ & SS $(n=59)$ & S/BThal $(n=33)$ & Controls $(n=118)$ \\
\hline Sex, F/M & $11 / 14$ & $29 / 30$ & $15 / 18$ & $41 / 77$ \\
\hline Age, years & $21.2 \pm 9.1$ & $16 \pm 9.9$ & $15.1 \pm 5.1$ & $20.6 \pm 5.5$ \\
\hline \multicolumn{5}{|c|}{ Hematological data } \\
\hline $\mathrm{Hb}(\mathrm{mg} / \mathrm{dL})$ & $12.9 \pm 1.67$ & $8.4 \pm 1.09$ & $8.32 \pm 1.33$ & $14.1 \pm 1.58$ \\
\hline $\mathrm{MCV}(\mathrm{fL})$ & $81.4 \pm 7.39$ & $87.4 \pm 8.0$ & $69.16 \pm 7.91$ & $85.2 \pm 4.08$ \\
\hline $\mathrm{MCH}(\mathrm{pg})$ & $26.78 \pm 2.91$ & $28.7 \pm 2.88$ & $23.34 \pm 3.41$ & $31.1 \pm 2.76$ \\
\hline $\mathrm{HbF}(\%)$ & $1.1 \pm 0.63$ & $5.14 \pm 3.3$ & $7.98 \pm 3.43$ & $0.9 \pm 0.23$ \\
\hline $\mathrm{HbS}(\%)$ & $36.3 \pm 6.1$ & $86.6 \pm 7.4$ & $69.8 \pm 10.56$ & 0 \\
\hline $\mathrm{Hb}$ A2 (\%) & $2.61 \pm 0.41$ & $2.1 \pm 0.52$ & $4.46 \pm 0.74$ & $2.4 \pm 0.52$ \\
\hline \multicolumn{5}{|c|}{ Clinical complications } \\
\hline DVT & 0 & 0 & 3 & 0 \\
\hline Stroke & 0 & 3 & 1 & 0 \\
\hline Priapism & 0 & 2 & 0 & 0 \\
\hline Leg ulcers & 0 & 9 & 0 & 0 \\
\hline AVN & 0 & 5 & 2 & 0 \\
\hline
\end{tabular}

$\mathrm{Hb}$ hemoglobin, $M C V$ mean corpuscular volume, $M C H$ mean corpuscular hemoglobin, $H b F$ hemoglobin $\mathrm{F}, H b S$ hemoglobin $\mathrm{S}, \mathrm{HbA2}$ hemoglobin $\mathrm{A} 2$. $A S$ Sickle cell trait, SS Sickle cell anemia, S/ $\beta$ Thal Sickle $\beta$-thalassemia, DVT deep vein thrombosis, AVN avascular bone necrosis 
age in two males presenting with sickle cell anemia (SS) (Table 1).

\section{Analysis of factor V Leiden G1691A mutation}

The frequency of FVL mutation in the study population and its association with SCD is summarized in Table 2. The FVL mutation in its homozygous and heterozygous forms was found in 20 out of 117 patients for an overall prevalence of $17 \%$. Analysis of the SS patients for the FVL mutation revealed that 11 of $59(18.64 \%)$ SS patients were heterozygotes (frequency of A allele 9.32\%), while none of the SS patients were homozygote for this mutation. Among the AS patients, one patient was heterozygote and one patient was homozygote for the FVL mutation with a prevalence of $8 \%$ and the frequency of A allele was $6 \%$. Analysis of the $\mathrm{S} /$ / $\mathrm{thal}$ patients revealed that 4 patients were heterozygotes and three were homozygotes for the FVL mutation with a prevalence of $21.21 \%$ and the frequency of A allele was $30.3 \%$. Among the control group, 18 individuals were heterozygotes and two were homozygotes for the FVL mutation (16.94\%) and the frequency of A allele was $9.32 \%$. Frequency of FVL genotypes in SS, AS and S/Bthal patients and controls revealed no statistically significant difference when compared with the predicted genotypes from the Hardy-Weinberg equilibrium ( $P$ values $0.92,0.90,0.89$, and 0.72 , respectively). Analysis of the association of gender with FVL mutation showed that among the SS patients, four males and seven females were heterozygotes of FVL mutation. While among the controls two males were homozygotes and 18 females were heterozygotes for FVL mutation. In the AS group, one male was heterozygote and another one was homozygote for the FVL mutation. While in S/Bthal patients, 2 females and 2 males were heterozygotes and 1 female and 2 males were homozygote for the FVL mutation. Taking the results of FVL mutation altogether, a significantly high prevalence of FVL was observed in Palestinian SS patients compared to controls.

Logistic regression analysis of age- and sex-adjusted data revealed a significant association between FVL mutation and sickle cell anemia $(\mathrm{OR}=5.6 ; 95 \% \mathrm{CI}=$ 1.91-39.4, $P=0.039$ ) in SS patients (Table 2). However, elevated prevalence of FVL in AS subjects and $S / \beta$ thal patients was not statistically significant when compared to controls $(\mathrm{OR}=3.97,95 \% \mathrm{CI}=$ $0.51-28.6, P=0.17$ and $\mathrm{OR}=3.59,95 \% \mathrm{CI}=0.35-41.6$, $P=0.26$, respectively).

Heterozygous FVL mutation was reported in one patient out of seven (14\%) with AVN documented by $\mathrm{X}$-ray, and the remaining 6 patients with AVN were normal for this mutation. The later differences were not statistically significant.

\section{Analysis of the prothrombin G20210A mutation}

The frequency of prothrombin G20210A mutation among the study population and its association with SCD is summarized in Table 3. None of the SCD patients were homozygous for prothrombin G20210A mutation, but 8 of the 117 patients were heterozygous for the mutation for an overall prevalence of $6.83 \%$. Heterozygous prothrombin G20210A mutation was found in 3 of 59 (5.08\%) SS patients (allele A frequency $2.54 \%$ ), one of 25 (4\%) AS subjects (allele A frequency 2\%), 4 of 33 (12.12\%) S/ $\beta$ thal patients (allele A frequency $6.06 \%$ ) and 6 of 118 (5.08\%) controls (allele A frequency 2.54\%). The frequency of prothrombin G20210A genotypes in SS, AS, and S/Bthal patients and controls revealed no significant difference when compared to the predicted genotypes from the Hardy-Weinberg equilibrium ( $P$ values $0.95,0.92,0.91$, and 0.83 , respectively). In SS patients, 3 males were carriers of prothrombin G20210A mutation while in 118 controls, 2 females possessed this mutation. In AS subjects one male carried the prothrombin G20210A mutation. While in S/ $\beta$ thal patients the mutation was found in 2 females and 2 males.

Logistic regression analysis of age- and sex-adjusted data showed that the prevalence of the prothrombin G20210A in SS, AS individuals and S/ $\beta$ thal patients, was not statistically significant compared to controls (OR 6.3, 95\% CI 1.17-33.9, $P=0.12$, OR 3.71, 95\% CI 0.4626.1, $P=0.18$ and OR $3.39,95 \%$ CI $0.33-43.4, P=0.21$, respectively) (Table 3 ).

Heterozygous prothrombin G20210A mutation was found in one of the 4 patients (25\%) with stroke, and the remaining 3 patients with stroke were normal for this mutation. But, the later differences were not statistically significant.

Table 2 Prevalence of factor V Leiden mutation and its association with SCD in Palestinian patients

\begin{tabular}{|c|c|c|c|c|c|c|c|}
\hline \multirow[t]{2}{*}{ Patient (n) } & \multicolumn{3}{|c|}{ FV Leiden } & \multicolumn{2}{|l|}{ Crude } & \multicolumn{2}{|l|}{ Adjusted } \\
\hline & $\overline{G / G}$ & $\mathrm{G} / \mathrm{A}$ & $\mathrm{A} / \mathrm{A}$ & OR (95\% Cl) & $P$ value & OR (95\% Cl) & $P$ value \\
\hline SS (59) & 48 & 11 & 0 & $9.31(2.1-61.9)$ & 0.027 & $5.6(1.91-39.4)$ & 0.039 \\
\hline AS (25) & 23 & 1 & 1 & $8.4(1.12-64.7)$ & 0.038 & $3.97(0.51-28.6)$ & 0.17 \\
\hline S/ßThal (33) & 26 & 4 & 3 & $7.2(0.63-75.4)$ & 0.19 & $3.59(0.35-41.6)$ & 0.26 \\
\hline Controls & 98 & 18 & 2 & 1 & - & 1 & - \\
\hline
\end{tabular}


Table 3 Prevalence of prothrombin G20210A mutation and its association with SCD in Palestinian patients

\begin{tabular}{|c|c|c|c|c|c|c|c|}
\hline \multirow[t]{2}{*}{ Patient $(n)$} & \multicolumn{3}{|c|}{ Prothrombin G20210A } & \multicolumn{2}{|l|}{ Crude } & \multicolumn{2}{|l|}{ Adjusted } \\
\hline & $\overline{G / G}$ & $\mathrm{G} / \mathrm{A}$ & $\mathrm{A} / \mathrm{A}$ & OR (95\% Cl) & $P$ value & $\overline{\mathrm{OR}}(95 \% \mathrm{Cl})$ & $P$ value \\
\hline SS (59) & 56 & 3 & 0 & $8.4(1.8-56.4)$ & 0.16 & $6.3(1.17-33.9)$ & 0.12 \\
\hline AS (25) & 24 & 1 & 0 & $5.5(1.1-66.2)$ & 0.13 & $3.71(0.46-26.1)$ & 0.18 \\
\hline S/Thal (33) & 29 & 4 & 0 & $9.4(1.9-54.4)$ & 0.09 & $3.39(0.33-43.4)$ & 0.21 \\
\hline Controls & 112 & 6 & 0 & 1 & - & 1 & - \\
\hline
\end{tabular}

\section{Clinical symptoms of SCD patients and thrombophilic mutations}

The clinical symptoms of SCD patients enrolled in this study are shown in Table 4. The association between clinical manifestation of SCD patients and the coinheritance of either the FVL or mutant allele of prothrombin G20210A was explored by chi-square analysis (Table 4). SCD patients having the FVL mutation showed a significantly higher incidence of pain in joints, chest and abdomen, as well as regular dependence on blood transfusion compared to SCD patients with the wild-type genotype. However, SCD patients having the mutant allele for prothrombin G20210A mutation showed no significant association with the clinical manifestations investigated in this study, except for blood transfusion, when compared to SCD patients with the wild-type genotype.

\section{Discussion}

Thrombosis is a common complication in patients with sickle cell disease, where coagulation and fibrinolytic abnormalities lead to the development of a hypercoagulability state in such patients [12]. Acute chest syndrome and occlusive strokes have been evidenced in patients with SCD as major causes of death, which results from previous thromboembolism events [3].

FVL and prothrombin G20210A are the major inherited risk factors for venous thrombosis and their presence increases the risk of thrombosis 5-10-folds among patients with deep venous thrombosis [13].

Nowadays, there is no single clinical or laboratory test that can predict which patients are at high risk for developing thrombotic complications of SCD. Inherited predisposition factors to thrombosis could coexist with other endothelial, erythrocyte, and coagulation abnormalities and leads to an increased risk of thrombotic complications [14]. However, the role of inherited thrombophilia in the pathogenesis of SCD has been tackled by few studies but the findings were not conclusive or even controversial. For example, a low prevalence of FVL and prothrombin G20210A was reported in SCD patients from Saudi Arabia representing Saudi nationals [15], Brazilians with African descent [16] or African Americans in the United States [17]. In contrast, a high prevalence of FVL but not prothrombin G20210A was reported among Indian [18] and Iranian SCD patients [19]. In the present study, a significantly higher prevalence of FVL was observed among SS patients compared to controls while the frequency of prothrombin G20210A mutation was not significantly different among SCD patients compared to controls. Our findings were consistent with previous reports concerning FVL and prothrombin G20210A $[18,19]$ but in contrast to other studies [15-17]. The different findings concerning prevalence of FVL and prothrombin G20210A among SCD patients may be partially due to the different

Table 4 Clinical symptoms observed among SCD patients with the FVL G1691A and prothrombin G20210A mutations versus SCD patients without these mutations. Results are expressed as frequency and percentages

\begin{tabular}{|c|c|c|c|c|c|c|}
\hline & FVL mutant $(N=20)$ & FVL wild $(N=97)$ & $P$-value & Prothrombin mutant $(N=8)$ & Prothrombin wild $(N=109)$ & $P$ value \\
\hline Joints pain & $16(80 \%)$ & $41(42.2 \%)$ & 0.0132 & $4(50 \%)$ & $55(50.4 \%)$ & $N S^{a}$ \\
\hline Chest pain & $18(90 \%)$ & $52(53.6 \%)$ & 0.006 & $4(50 \%)$ & $57(52.2 \%)$ & NS \\
\hline Abdominal pain & $14(70 \%)$ & $48(49.5 \%)$ & 0.0311 & $4(50 \%)$ & $61(55.9 \%)$ & NS \\
\hline Splenomegaly & $18(90 \%)$ & $53(54.6 \%)$ & 0.0071 & $3(37.5 \%)$ & $49(44.9 \%)$ & NS \\
\hline \multicolumn{7}{|c|}{ Frequency of Blood transfusion (no./year) } \\
\hline $0-2$ & $2(10 \%)$ & $21(21.6 \%)$ & NS & $1(12.5 \%)$ & $29(26.6 \%)$ & NS \\
\hline $3-5$ & $3(15 \%)$ & 7 (7.2\%) & 0.047 & $2(25 \%)$ & 45 (41.3\%) & NS \\
\hline $6-9$ & $11(55 \%)$ & $4(4.1 \%)$ & 0.018 & $4(50 \%)$ & 23 (21.1\%) & 0.003 \\
\hline$\geq 10$ & $1(5 \%)$ & $0(0 \%)$ & NS & - - - - & -——- - & - - \\
\hline
\end{tabular}

${ }^{\mathrm{a} N S}$ not significant 
genetic background of the different ethnicities of study patients as well as the limited sample size in some studies.

In the present study, we also examined the role of inherited mutations FVL and prothrombin G20210A in the thrombotic complications of Palestinian SCD patients. Inherited risk factors for vascular disease, including venous as well as arterial thrombosis, have been described in the world population [20, 21]. However, the risk factor resulting from the prothrombin gene variant was distributed similarly among patients of Caucasian descent as well as patients of African descent [22].

In this study, the development of thrombosis and occlusive stroke were compared and no distinct prevalence of the risk factors was found. This is in agreement with the lack of correlation between FVL mutation and cerebral ischemia among patients with SCD [17], as well as in the general population. Also, the presence of chronic complications was not related to the presence of risk factors studied. In addition, our results indicated a higher incidence of pain and increased dependence on blood transfusion among SCD patients with FVL. While SCD patients with prothrombin G20210A mutation showed a significant association with increased dependence on blood transfusion but no significant association with pain in chest and joints and splenomegaly.

The high prevalence rate of FVL among healthy subjects from Palestine was interestingly matched with similarly high rates from neighboring Jordan [23], Israeli Arabs [24] and Lebanon [25]. This suggested that FVL mutation must have originated as a single mutational event outside of Europe, then spreading by migration of mutation-carrying individuals [26].

Prothrombin G20210A mutation was also present among healthy controls from Palestine, but at a lower frequency than FVL. Our results (2.54\%) were comparable to that reported for communities of Caucasian descent, including Turkey (2.7\%) [27] and Italy (3.2\%) [28].

\section{Conclusions}

This study is the first report that shows the prevalence and clinical impact of FVL and prothrombin G20210A mutations among Palestinian SCD patients. FVL was more prevalent among SS patients compared to normal subjects (control group). SCD patients with FVL showed a significantly higher incidence of pain in chest, abdomen and bone joints making these SCD patients dependent on regular blood transfusion to modify the vasoocclusive crises. The high frequency of FVL and its significant correlation with sickle cell anemia from Palestine could be an important risk factor for developing occlusive crisis. Studies that include a larger number of patients and controls are necessary to define specific guidelines. It is still possible that other inherited thrombophilic mutations may contribute to thrombotic complications in SCD. Mutations and polymorphisms in the fibrinogen gene, C677T mutation in the methylenetetrahydrofolate reductase (MTHFR) gene, C1565T mutation in the platelet glycoprotein IIIa (GPIIIa) gene, and factor VII gene and others should be analyzed to determine the contribution of inherited thrombophilic mutations to thrombotic complications in patients with SCD.

\section{Abbreviations \\ AS: Sickle cell trait; AVN: Avascular bone necrosis; Cl: Confidence interval; FVL: Factor V Leiden; GPIIla: Platelet glycoprotein Illa gene; MTHFR: Methylene tetrahydrofolate reductase; OR: Odds ratio; RDB-PCR: Reverse dot blot polymerase chain reaction; RFLP PCR: Restriction fragment length polymorphism - polymerase chain reaction; SCD: Sickle cell disease; SS: Homozygote sickle cell anemia; $\beta^{\text {S: Hemoglobin S }}$}

\section{Acknowledgments}

The authors are grateful to the staff of the Thalassemia and Hematology departments at Al-Watani hospital/Nablus and the Palestinian Ministry of Health for their help in patient's recruitment and sample collection.

\section{Funding}

None

Availability of data and materials

The datasets used and/or analysed during the current study are available from the corresponding author on reasonable request.

\section{Authors' contributions}

FS conducted experimental design, sample collection and analysis, data interpretation and manuscript writing. MAS conducted experimental design, interpretation of data and was a major contributor to manuscript writing. Both authors read and approved the final manuscript.

\section{Authors' information}

FS is an assistant professor of Hematology at the Department of Medical Technology, Faculty of Allied Health Sciences, Arab American University, Jenin, Palestine. Tel.: +970(4)2510801/2/3/4/5/6; Fax: +970(4)2510810; E-mail: fekri.samarah@aauj.edu.

MAS is an assistant professor at the Department of Medical Laboratory Sciences, Faculty of Health professions, Al-Quds University, Jerusalem, Palestine.Tel/Fax: +970 2241 4076. E-mail: msrour@yahoo.com. Present address: Department of Biology \& Biochemistry, Faculty of Science, Birzeit University, Birzeit, Palestine.

\section{Ethics approval and consent to participate}

This study was approved by the Research Ethics Committee at Al-Quds University according Helsinki declaration. A written informed consent was obtained from individual participants or from legal guardian in case of minors (less than 16 years old) for all persons included in this study.

Consent for publication

Not applicable.

\section{Competing interests}

The authors declare that they have no competing interests.

\section{Publisher's Note}

Springer Nature remains neutral with regard to jurisdictional claims in published maps and institutional affiliations.

\section{Author details}

'Department of Medical Technology, Faculty of Allied Health Sciences, Arab American University in Jenin, Jenin, Palestine. ${ }^{2}$ Department of Medical Laboratory Sciences, Faculty of Health professions, Al-Quds University, Jerusalem, Palestine. ${ }^{3}$ Present address: Department of Biology \& Biochemistry, Faculty of Science, Birzeit University, Birzeit, Palestine. 
Received: 16 August 2017 Accepted: 4 January 2018

\section{Published online: 16 January 2018}

\section{References}

1. Stuart MJ, Nagel RL. Sickle-cell disease. Lancet. 2004;346:1343-60.

2. Kutlar A, Kutlar F, Turker I, Tural C. The methylene tetrahydrofolate reductase (C667T) mutation as a potential risk factor for avascular necrosis in sickle cell disease. Hemoglobin. 2001;25:213-7.

3. Manci EA, Culberson DE, Yang YM, Gardner TM, Powell R, Haynes J Jr, et al. Investigators of the cooperative study of sickle cell disease. Causes of death in sickle cell disease: an autopsy study. Br J Haematol. 2003;123:359-65.

4. Montes RA, Eckman JR, Hsu LL, Wick TM. Sickle erythrocyte adherence to endothelium at low shear: role of shear stress in propagation of vaso-occlusion. Am J Hematol. 2002;70:216-27.

5. Andrade FL, Annichino-Bizzacchi JM, Saad STO, Costa FF, Arruda VR. Prothrombin mutant, factor $V$ Leiden, and thermolabile variant of methylenetetrahydrofolate reductase among patients with sickle cell disease in Brazil. Am J Hematol. 1998;59:46-50.

6. Weingarz $L$, Schindewolf $M$, Schwonberg J, Hecking $C$, Wolf $Z$, Erbe $M$. Thrombophilia and risk of VTE recurrence according to the age at the time of first VTE manifestation. Vasa. 2015;44(4):313-23.

7. Poort SR, Rosendaal FR, Reitsma PH, Bertina RM. A common genetic variation in the '3-untranslated region of the prothrombin gene is associated with elevated plasma prothrombin levels and an increase in venous thrombosis. Blood. 1996;88(10):3698-703.

8. Wild BJ, Bain BJ. Investigation of abnormal hemoglobins and thalassemia. In: Bain BJ, Bates I, Laffan MA, Lewis SM, editors. Dacie and Lewis practical Haematology. 11th ed. London: Elsevier Churchill Livingstone; 2011. p. 301-32.

9. Kulozik AE, Lyons J, Kohne E, Bartram CR, Kleihaur E. Rapid and non radioactive prenatal diagnosis of $\beta$-thalassemia and sickle cell disease: application of the polymerase chain reaction (PCR). Br J Haematol. 1988;70(1):455-8.

10. Samarah F, Ayesh S, Athanasiou M, Christakis J, Vavatsi N. Beta(S)-Globin gene cluster haplotypes in the West Bank of Palestine. Hemoglobin. 2009:33(2):143-9.

11. Bhardwaj U, Zhang YH, Lorey F, McCabe LL, McCabe ER. Molecular genetic confirmatory testing from newborn screening samples for the common African-American, Asian Indian, southeast Asian, and Chinese beta-thalassemia mutations. Am J Hematol. 2005:78(4):249-55.

12. Kenneth IA, Eugene PO. Hypercoagulability in sickle cell disease: a curious paradox. Am J Med. 2003;115:721-8.

13. Klaassen IL, van Ommen $\mathrm{CH}$, Middeldorp S. Manifestations and clinical impact of pediatric inherited thrombophilia. Blood. 2015;25(7):1073-7.

14. Pandey SK, Meena A, Kishor K, Mishra RM, Pandey S, Saxena R. Prevalence of factor V Leiden G1691A, MTHFR C677T, and prothrombin G20210A among Asian Indian sickle cell patients. Thromb Hemost. 2012;18(3):320-3.

15. Fawaz NA, Bashawery L, Al-Sheikh I, Qatari A, Al-Othman SS, Almawi WY. Factor V-Leiden, prothrombin G20210A, and MTHFR C677T mutations among patients with sickle cell disease in eastern Saudi Arabia. Am J Hematol. 2004;76:307-9.

16. Neto FM, Lourenco DM, Noguti MAE, Morelli VM, Gil ICP, Beltrao ACS, Figueiredo MS. The clinical impact of MTHFR polymorphism on the vascular complications of sickle cell disease. Braz J Med Biol Res. 2006;39:1291-5.

17. Mj K, Scher C, Rozans M, Michaels RK, Leissinger C, Krause J. Factor V Leiden is not responsible for stroke in patients with sickling disorders and is uncommon in African Americans with sickle cell disease. Am J Hematol. 1997;54:12-5.

18. Nishank SS, Singh MPSS, Yadav R. Clinical impact of factor V Leiden, prothrombin G20210A and MTHFR C677T mutations among sickle cel disease patients of central India. Eur J Haematol. 2013;91:462-6.

19. Rahimi Z, Raygani AV, Nagel RL, Muniz A. Thrombophilic mutations among southern Iranian patients with sickle cell disease: high prevalence of factor $V$ Leiden. J Throm Thrombolys. 2008;25:288-92.

20. De Stefano V, Finazzi G, Mannucci PM. Inherited thrombophilia: pathogenesis, clinical syndromes and management. Blood. 1996;87(9):3531-344.

21. Lane DA, Mannucci PM, Bauer KA, Bertina RM, Bochkov NP, Boulyjenkov V, et al. Inherited thrombophilia: part 1. Thromb Haemost. 1996;76(5):651-62

22. Arruda VR, Annichino-Bizzachi JM, Goncalves MS, Costa FF. Prevalence of the prothrombin gene variant (20210A) in venous thrombosis and arterial disease. Thromb Haemost. 1997;78(6):1430-3.
23. Eid SS, Rihani G. Prevalence of factor V Leiden, prothrombin G20210A and MTHFR C677T mutations in 200 healthy Jordanians. Clin Lab Sci. 2004;17(4):200-2.

24. Rosen E, Renbaum P, Heyd J, Levy-Lahad E. High frequency of factor V Leiden in a population of Israeli Arabs. Thromb Haemost. 1999;82(6):1768.

25. Almawi WY, Keleshian SH, Borgi L, Fawaz AN, Abboud N, Mitraoui N, et al. Varied prevalence of factor V G1691A (Leiden) and Prothrombin G20210A single nucleotide polymorphisms among Arabs. J Thromb Thrombolys. 2005;20(3):163-8.

26. Zivelin A, Griffin JH, Xu X, Pabinger I, Samama M, Conard J, et al. A single genetic origin for a common Caucasian risk factor for venous thrombosis. Blood. 1997;89:397-402.

27. Batioglu F, Atmaca LS, Karabulut HG, Beyza Sayin D, Factor V. Leiden and prothrombin gene G20210A mutations in ocular Behcet disease. Acta Ophthalmol Scand. 2003;81:283-5.

28. Atherosclerosis, Thrombosis, and Vascular Biology Italian Study Group. No evidence of association between prothrombotic gene polymorphisms and the development of acute myocardial infarction at a young age. Circulation. 2003:107:1117-22

\section{Submit your next manuscript to BioMed Central and we will help you at every step:}

- We accept pre-submission inquiries

- Our selector tool helps you to find the most relevant journal

- We provide round the clock customer support

- Convenient online submission

- Thorough peer review

- Inclusion in PubMed and all major indexing services

- Maximum visibility for your research

Submit your manuscript at www.biomedcentral.com/submit
) Biomed Central 